\title{
Adrenal suppression and Cushing's syndrome secondary to ritonavir and budesonide
}

\author{
D Gray, P Roux, M Carrihill, M Klein
}

To the Editor: Ritonavir is a protease inhibitor used in combination therapy for advanced HIV infection. In South Africa lopinavir/ritonavir is first-line therapy for children under 3 years of age where there is a history of perinatal exposure to the non-nucleoside reverse transcriptase inhibitor (NNRTI) nevirapine. ${ }^{1}$ Ritonavir is a potent inhibitor of hepatic cytochrome P450-CYP3A4 iso-enzyme activity.

Inhaled or intranasal corticosteroids are commonly used in children with recurrent lower airways obstruction, allergic rhinitis and chronic obstructive airways disease. Although systemic absorption of inhaled corticosteroids occurs, sideeffects are uncommon at low or medium doses.

Inhaled corticosteroids are metabolised by hepatic CYP3A4. Fluticasone, a corticosteroid used in children, is known to interact with ritonavir, resulting in high levels of corticosteroids, suppression of the adrenocortical axis and Cushing's syndrome. ${ }^{2}$ There have been no reports of other inhaled corticosteroids causing adrenal suppression and Cushing's syndrome. Budesonide and beclomethasone are reported to be associated with a lower risk of systemic sideeffects than fluticasone, ${ }^{3}$ and a literature review suggested that they be used as an alternative to fluticasone given the risk of suppression of the adrenocortical axis. ${ }^{2}$

We report 3 cases of children presenting with a suppressed adrenocortical axis and Cushing's syndrome as a consequence of budesonide and ritonavir co-therapy.

\section{Case reports}

Case 1. A 4-year-old girl with perinatally acquired HIV infection had shown a good response to antiretroviral therapy over 29 months (HIV viral load $<50$ copies $/ \mathrm{ml}$ ). She received inhaled budesonide for recurrent cough and bronchodilatorresponsive wheeze and was later prescribed intranasal budesonide for allergic rhinitis. Her maximum daily dose of

Paediatric HIV Service, Groote Schuur Hospital, Cape Town, and Department of Pulmonology, Red Cross War Memorial Children's Memorial Hospital, Cape Town D Gray, MB ChB, DCH, FRACP (Paed)

Paediatric HIV Service, Groote Schuur Hospital, and School of Child and Adolescent Health, University of Cape Town

P Roux, MB ChB, MPhil (Bioethics), MD, DCH, FCP (Paed)

Paediatric HIV Service and Department of Paediatric and Adolescent Endocrinology, Groote Schuur Hospital

M Carrihill, MB ChB, DCH, FCP (Paed), Cert Endo \& Metab (SA) Paeds, MPhil (Paeds Endo)

School of Child and Adolescent Health, University of Cape Town, and Department of Pulmonology, Red Cross War Memorial Children's Hospital

M Klein, MB ChB, FCP (Paed)

Corresponding author: D Gray (diane.gray@uct.ac.za) budesonide was $1200 \mu \mathrm{g}$ and her daily dose of ritonavir was $300 \mathrm{mg} / \mathrm{m}^{2}$. She received no other cytochrome P450 inhibitors. After 3 months of inhaled and intranasal steroid she had facial lipohypertrophy, truncal obesity and facial hirsutism. Her inhaled steroid dose was decreased to $200 \mu \mathrm{g}$. One week later her early-morning cortisol level was less than $1 \mathrm{mmol} / \mathrm{l}$. All budesonide therapy was stopped. Three weeks later her earlymorning cortisol level was $222 \mathrm{mmol} / \mathrm{l}$.

Case 2. A 4-year-old girl with perinatally acquired HIV1 infection had responded well to lopinavir/ritonavir-containing antiretroviral therapy for 30 months (HIV viral load $<50$ copies $/ \mathrm{ml}$ ). She was diagnosed with bronchiolitis obliterans following severe recurrent lower respiratory tract infections and was managed on $200 \mu \mathrm{g}$ budesonide daily. Her total daily dose of ritonavir was $235 \mathrm{mg} / \mathrm{m}^{2}$. She developed facial and truncal obesity, facial hirsutism and a buffalo hump after 2 years on treatment with inhaled steroids. Blood pressure and blood sugar were normal. Her early-morning cortisol level was $8 \mathrm{mmol} / \mathrm{l}$. The lopinavir/ritonavir was switched to efavirenz. Her early-morning cortisol level was $278 \mathrm{mmol} / 1$ when repeated 4 weeks after stopping ritonavir.

Case 3. A 7-year-old boy with perinatally acquired HIV1 infection and post-infective chronic obstructive airways disease had had a good response to antiretroviral therapy for 59 months (HIV viral load $<50$ copies $/ \mathrm{ml}$ ). He had symptoms of recurrent lower airway obstruction on a background of chronic obstructive airways disease following previous severe bacterial pneumonia and tuberculosis. On prescribed inhaled fluticasone $50 \mu \mathrm{g}$ and salmeterol he developed facial and truncal obesity, a buffalo hump and facial hirsuitism within 2 months. His early-morning cortisol level was less than $1 \mathrm{mmol} / \mathrm{l}$. Fluticasone was replaced with budesonide at $100 \mu \mathrm{g}$ twice daily. One month after replacing fluticasone with budesonide there was no improvement in the phenotypic features and he had a persistently suppressed adrenal cortical axis (earlymorning cortisol $5 \mathrm{mmol} / \mathrm{l}$ ). It is interesting to note that even with the Cushing's symptoms his recurrent respiratory signs and symptoms persisted. Two weeks after stopping inhaled steroid therapy a repeat early-morning cortisol level was 5 $\mathrm{mmol} / \mathrm{l}$, and a further 4 weeks later it was $115 \mathrm{mmol} / \mathrm{l}$. An adrenocorticocotrophic hormone (ACTH) stimulation test showed a moderate response.

\section{Discussion}

Adrenal suppression with ritonavir and concomitant fluticasone has been described in children and adolescents, ${ }^{2,4}$ and it has been suggested that other inhaled corticosteroids such as budesonide may be safer, given the comparatively prolonged clearance of fluticasone.

Our cases demonstrate that budesonide, which is also metabolised by iso-enzyme CYP3A4, can produce adrenal 
suppression when used with ritonavir/lopinavir. HIV-infected children have a high incidence of chronic lung disease, which includes chronic obstructive respiratory disease. ${ }^{5}$ Given the large number of children who are prescribed ritonavircontaining antiretroviral regimens, many may be exposed to co-treatment with budesonide.

The daily dose of budesonide used in our cases varied from $200 \mu \mathrm{g}$ to $1200 \mu \mathrm{g}$. Adherence to medication was assessed by verbal report and medication demonstration by the caregiver. In case 2 the child was given medication by a trained nurse in a children's home and medication was boarded for us to review. Dosing of inhaled budesonide in children with obstructive lung disease is based on clinical response to treatment. Recommended dosing ranges from a low dose of $100-200 \mu \mathrm{g} / \mathrm{d}$ to higher doses of $>400 \mu \mathrm{g} / \mathrm{d}$. With the exception of case 1 these children were on moderate doses of budesonide only and in case 3 initially a low dose of fluticasone $(50 \mu \mathrm{g} / \mathrm{d})$. The fact that the children may have been overdosed cannot be entirely excluded. However, it appears that adrenal axis suppression can occur at standard recommended doses of budesonide and fluticasone when used concomitantly with ritonavir. This relationship requires further investigation.
The older nucleoside reverse transcriptase inhibitors (NRTIs) such as zidovudine and stavudine remain first-line therapy in our and other resource-limited settings. These drugs are associated with lipodystrophy and truncal obesity. It is important to consider Cushing's syndrome as a differential diagnosis and that the diagnosis of adrenal suppression is not missed. ${ }^{6}$

The combination of ritonavir and inhaled corticosteroids should be avoided. If co-therapy is necessary, careful physical examination and monitoring of adrenal axis function are essential.

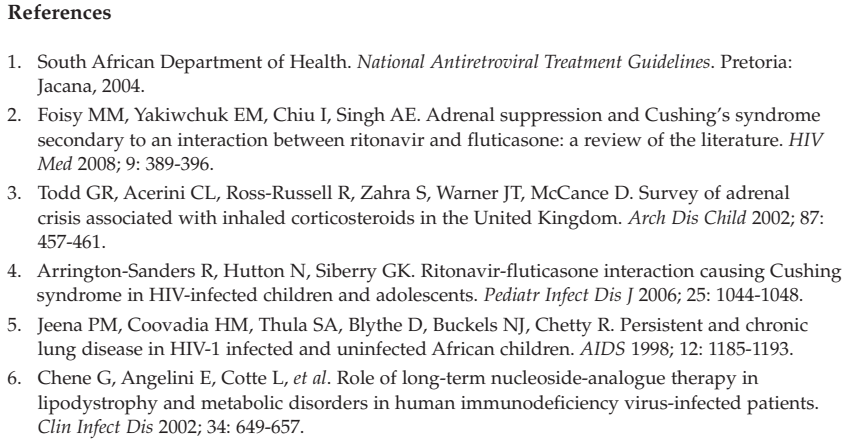

4. Arrington-Sanders R, Hutton N, Siberry GK. Ritonavir-fluticasone interaction causing Cushing syndrome in HIV-infected children and adolescents. Pediatr Infect Dis J 2006; 25: 1044-1048.

5. Jeena PM, Coovadia HM, Thula SA, Blythe D, Buckels NJ, Chetty R. Persistent and chronic lung disease in HIV-1 infected and uninfected African children. AIDS 1998; 12: 1185-1193.

6. Chene G, Angelini E, Cotte L, et al. Role of long-term nucleoside-analogue therapy in lipodystrophy and metabolic disorders in human immunodeficiency virus-infected patients. Clin Infect Dis 2002; 34: 649-657.

\title{
High prevalence of hookah smoking among secondary school students in a disadvantaged community in Johannesburg
}

\author{
A Combrink, N Irwin, G Laudin, K Naidoo, S Plagerson, A Mathee
}

To the Editor: Smoking of hookahs (also known as water-pipes) represents an emerging trend in tobacco use. ${ }^{1}$ Hookah smokers are at risk for the same diseases caused by cigarette smoking cancer, respiratory and heart diseases, and pregnancy-related complications. Globally, the highest rates occur in the North African and East Mediterranean regions and among young people in the USA and European countries. ${ }^{2}$ There has been little research on hookah smoking in southern Africa.

Faculty of Health Sciences, University of the Witwatersrand, Johannesburg A Combrink, $\mathrm{MB} \mathrm{ChB}$

N Irwin, MB ChB

G Laudin, MB ChB

K Naidoo, MB ChB

Environment and Health Research Unit, South African Medical Research Council, Johannesburg

S Plagerson, $\mathrm{PhD}$

Environment and Health Research Unit, South African Medical Research Council, Johannesburg, and Faculty of Health Sciences, University of Johannesburg A Mathee, $\mathrm{PhD}$

\section{Methods}

The Health, Environment and Development study, ${ }^{3}$ conducted by the South African Medical Research Council in five deprived areas of Johannesburg, observed surprisingly high rates of smoking in a community near the centre of Johannesburg. Anecdotal reports and direct observations pointed to a high frequency of hookah smoking as a possible explanation. Subsequently, undergraduate medical students of the University of the Witwatersrand were invited to conduct a health education workshop on the effects of hookah smoking in the secondary school serving this community. To inform the workshop, a baseline survey was conducted among the student population. All Grade 10 students were invited to participate. Approval to conduct the study was obtained from the school principal, and verbal consent was obtained from the individual students, following an explanation that the study was voluntary and anonymous and that the results would be used for research purposes only. The ages of participants $(N=202)$ in the four classes were from 14 - 20 years (mean 16.3 years). Three students elected not to participate. 